\title{
Failure to Innovate is the Key Reason for Failure
}

\author{
Robert W (Bill) Service* \\ Brock School of Business, Samford University, USA
}

*Corresponding author: Robert W (Bill) Service, Professor of Management and Leadership, Brock School of Business, Samford University, 800 Lakeshore Drive, Birmingham, AL 35229 USA.

Received Date: June 12, 2020

Published Date: June 30, 2020

\section{Editorial}

There are two overriding organizational and personal imperatives to sustainability: 1) understanding why someone would do business with you or your organizations-a distinctive; and 2) how to become and remain innovative organizationally and personally- innovativeness. As we address the current state of affairs with the world-wide pandemic and compellingly difficult race issues in the U.S. keep these imperatives in mind.

The summer of 2020 finds the world in a perfect storm of disconcerting academic and societal issues combined with "global weirding" of vocations enabled by rapid changes with artificial intelligence and a wide-open internet's zettabyte of data accessible on demand. These earth shattering events are occurring under the societal issues that surfaced with a human brutality most never have witnessed and a pandemic the like of which has not been seen for over a 100 years. Strategic moves under these combined events require understanding of overriding whys and the need for new approaches. Advancements and unrest show no sign of slowing. In the vocational area, the use of "cobots" (robots that collaborate) in the last bastion of distinction where innovative endeavors are being replaced by non-humans. In the social arena, justice and equality must go beyond words to actions.

Relative to employment, teaching and knowledge, we are on the brink of linking human thinking with the power of all search engines. This might make obsolete traditional intellect and education? In fact, the science fiction of my youth has become reality in many areas, extending organizational and individual capabilities and sadly in some cases inequality. We all must work and change to meet the new and coming future where it is going as opposed to where it has been.
Those occupational, educational, organizational and personal vocational issues are being attacked by viruses of the mind that surround every thought and action: solutions must be found for vocational shifts and mindset shifts on justice and equality. This current author provides no specific answers here and is absolutely sure of only one thing: "I might be wrong."

My answer for finding more possible solutions starts here in the academy of thought and publishing. We must move the greater academic of social sciences away from the publishing of nitty gritty overly academic articles that few read, where almost none can be replicated and the topics are as narrow as to be of no significance. Academia in all of social science from business- leadershipmanagement-relationship- to psychology and all non-STEM disciplines must began to put its brainpower behind developing many alternatives to solving the problems facing the world - race relations, worldwide economic stagnation, burgeoning killer viruses, new economic and population worries, mounting national debt, abuses of power and bulling, and a resurgence of violent extremism to name a few - the need to develop and implement new strategies is apparent. Perhaps the best examples of focused academia minds come from the WWII breaking of the 'Enigma' code at Bletchley Park: research this for yourself.

\section{So What and How?}

First and foremost shift teaching, leading and managing toward critical thinking and addressing critical issues of the day for without a calm and open society organizational benefits will be meaningless. Second, shift academic research and publication toward addressing critical societal issues with the idea of presenting alternatives that can be used in other arenas. Third, develop real partnerships 
with business and non-profit organizations to jointly develop solutions with strategic plans to implement and test beyond the organizations strategic product and service: move toward building a better society for all. Fourth, reward all the efforts noted above; and reduce conflict over ideas and words. Remember always that any strategy must revolve around innovation. That is, discovering new combinations and transformations for concepts and things that already exist: what worked or did not work in one context becomes a solution in another context. Help strategist in making a habit of looking at issues, problems, and opportunities from many angles encouraging them to simplify by forming multiple analogies in order to re-redirect their thinking. In reality, humans have never created anything; we merely rearranged things. Think of what Leonardo da Vinci said of many of his works: 'it' was there in the stone and I only removed the parts that were not 'it.

\section{Zoom in and Out}

Focused, intentional engagement is key, and people get engaged when they buy into a purpose, realize what is in it for them or their loved ones, are given autonomy, and they master an area of interest. A foundational start to ever more innovation has to be more broadly shared goals with appropriate incentives plus: focusing on the user, sharing with all and accepting ideas regardless of source. Most any and everything are not right or wrong in all cases, but normally just different: avoid the dichotomies of the 'influential's' in our society. Demand news beyond views- make the so-called news become informers not influencers. Use data to inform not confirm. Think and act big and small- the pixels and its picture both matter. Learn to embrace and celebrate the well-conceived failure. Shift data analytics from getting it to say what you want to hear toward listening to what it says. Engage imagination with the 'whys' to focus more closely and more distantly on the picture and its pixels. Admit to the reality that "I might be wrong." Do not do as everyone else does as they predominantly seek confirming evidence; instead explore, "What if I am wrong?" Regardless of one's reality, we must work with the reality that what the critical mass of our constituents perceives are their realities.

\section{So Whatand How? Innovate Strategic Distinctiveness Through Actions that Center on:}

1. Relationships rule; help everyone achieve more from what they have and are,

2. Self-awareness coupled with development-org learning,

3. Applied Reality, Emotional, Successful, Knowledge = intellectual wisdom,

4. New products/services or processes (R\&D),

5. Best or better quality (TQM)- service or products, betterbest procurement (JIT),

6. Most, new, different or better features, new or varied aspects of functionality,
7. Price-considering price performance relationships,

8. Fitness of use from many views; include multi-faceted uses,

9. Locational aspects-where and convenience; and varied cultural considerations,

10. Delivery characteristics and alternatives,

11. Liability shifting arrangements,

12. New ways to build, buy or rent- co-create

13. Tech-AI, cobots, apps, expanded telecom,

14. Status perceived: compared to substitutes- imitationsother choices: value,

15. Perceptions-marketing and fads,

16. Cost benefit analysis changes-opportunity costs, tradeoffs or shifts,

17. Appearance, perceived and otherwise- for fitness of use,

18. Character, ethics, trust, truth, trustworthiness, truthfulness,

19. Leadership \& management-polices, rules, mindsets, views; HRM,

20. Flexible strategic fit, balance, appropriateness.

Overall everything works better when people care, are engaged and take action. Fail fast experimentation and redefining normal for any of the 20 possibilities shown above can work. Moreover, look to develop combinations, permutations, sub-set, super-set of all of the above as you seek additive, divisional, multiplicative, exponential, factor, factorial, etc. manipulations. Competitive advantages come through the prior percepts intertwined with intangibles to form a sustainable distinctive.

\section{Where are we now? Why is this Important?}

We often hear that we are in a time of great turbulence and indeed we are: always has been and always will be. But, now there is a new slant to our troubling times. So many if not most of those major concerns are not 'third worldly', but mostly first world type issues, that is, the most troubling of major issues are man-made with huge improvements within human possibilities. It can be said that nothing breeds human faltering like affluence; likewise, nothing produces failure like success. Yes, we have the economic wealth, knowledge and related means to solve world hunger, health care, employment, drug abuse, crime, immigration, education, social issues, climate and many other pressing issues of our time. However, we do not have the will nor do we use- with any degree of effectiveness- our academic research toward addressing those issues. That needs to become a priority for academia or academia will slip further from relevance. At one time academia leads the world in discoveries and new areas of thought. In my experience 
and in the minds of many, academia has slipped off those top 'influential' slots.

In life 'things' happen all around us and if we observe and seek lessons we will find those that will add value, to us, those around us and our situations. But only if we are informed and question enough to discern real lessons not presenting complaints. Valuable lessons or disruptive twaddle, it is the receiver's responsibility to decide. So often we say or hear the words 'I'm offended' as a replacement for 'please' as the way to get our way. No one can really teach any of us anything, but we can learn almost anything. Remember, a 'teacher' only arrives when a 'student' is ready for that lesson.

\section{So what? So why? So how? But most Importantly, So now?}

The keys to good discovery inquiry and development of solid alternatives starts with judgment and includes curiosity, patience, creativity and the courage to venture into the unknown. Beyond admitting 'I might be wrong,' is the need to forever ask: "How do I know when I know?" Knowing enough to act must be balanced with the process of 'the' forever inquiry scientific mindset. Awareness of what, why and how are virtually unless until one acts. And remember always, that by thinking to learn we learn to think. In the end, your mindset must be around distinctive and innovation if we are to advance more solid solutions to the most pressing of problems. So why?

Learning is observing, generalizing and reflecting; and the worth of knowledge that works only comes from making and accepting feedback. Once you know something you can do, and once doing becomes a habit you can become. Become an innovative leader who is dedicated to building other leaders that will address the tough issues, make the hard calls and make it a better world for all. Shift mindsets, strategic actions, academic publication, teaching and all forms of education toward forever purposeful, principled progress. Commit to become and remain a person of influence. If not now, when?

\section{Acknowledgement}

None.

\section{Conflict of Interest}

None. 